\title{
Effects of and challenges to bans on menthol and other flavors in tobacco products
}

\author{
Krzysztof Przewoźniak ${ }^{1,2,3}$, Christina N. Kyriakos ${ }^{4}$, Rosemary Hiscock ${ }^{5}$, Cornel Radu-Loghin ${ }^{6}$, Geoffrey T. Fong ${ }^{7,8}$
}

In May 2020, the European Tobacco Products Directive (TPD), which bans characterizing flavors in cigarettes and roll-your-own tobacco (RYO) in the European Union (EU), extended its application to menthol ${ }^{1,2}$. Countries which were early adopters of flavor bans include Brazil, Canada, Ethiopia, the United Kingdom (UK), amongst others ${ }^{3}$. Two main regulatory approaches exist: a ban on characterizing flavors that allows for the presence of additives but not at detectable sensory levels (e.g. EU, UK), and a total ban on flavor additives that eliminates their presence altogether (e.g. Brazil, Canada). As more countries work towards adopting tobacco flavor bans, it is critical to understand how these policies are implemented, ascertain their population-level impact, and identify the regulatory challenges.

Initial evaluation of these bans has provided evidence for their positive impact as well as the challenges. Population-level data from the International Tobacco Control (ITC) Surveys in Canada and Europe have demonstrated that banning menthol and other flavors in cigarettes can lead to positive public health outcomes including increased quitting, without significant unintended consequences such as illicit purchasing ${ }^{4,5}$. The menthol cigarette ban in Canada led to $7.5 \%$ additional quitting among menthol smokers compared to nonmenthol smokers ${ }^{4}$. Findings from the EUREST-PLUS ITG Europe Surveys, before and after the flavor ban, but prior to the menthol ban, found a reduction in menthol use ${ }^{5}$ as well as other flavors and improved health knowledge and beliefs among menthol smokers. However, a majority of menthol smokers in Canada switched to non-menthol cigarettes rather than quitting, and a substantial proportion of EU smokers continued to smoke menthol cigarettes prior to the ban and intended to either continue or switch to non-menthol cigarettes after the menthol ban, rather than quit ${ }^{4,5}$. This is not surprising, given the high addictiveness of cigarettes, coupled with the lack of promotion and availability of smoking cessation support, and the measures taken by the tobacco industry to circumvent and undermine menthol bans ${ }^{6}$.

In response to menthol bans, the industry has introduced menthol products that remain legal post-ban ${ }^{6}$, such as menthol cigarillos, menthol accessories sold separately (e.g. menthol-infused cards, filter capsules, and RYO papers and filters) and new cigarette blends with low levels of menthol ${ }^{6}$. This raises the question of whether a characterizing flavor ban, compared to a total additive ban, allows a gap where the industry-desirable properties of additives, such as the cooling effect of menthol, could operate at a subliminal level. Some EU Member States, such as Germany and Finland, have gone beyond the current TPD by prohibiting menthol as an additive at any level, based on the evidence that it facilitates inhalation ${ }^{7}$. Other questions remain: 'To what extent can current methodologies for determining the presence of characterizing flavors

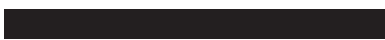

AFFILIATION

1 Maria Skłodowska-Curie National Research Institute of Oncology, Warsaw, Poland

2 Health Promotion Foundation, Nadarzyn, Poland

3 Collegium Civitas, Warsaw, Poland

4 Department of Primary Care and Public Health, School of Public Health, Imperial College London, London, United Kingdom 5 Tobacco Control Research Group, Department for Health, University of Bath, Bath, United Kingdom 6 European Network for Smoking and Tobacco Prevention, Brussels, Belgium

7 Department of Psychology, School of Public Health Sciences, University of Waterloo, Waterloo, Canada

8 Ontario Institute for Cancer Research, Toronto, Canada

\section{CORRESPONDENCE TO}

Christina N. Kyriakos. Department of Primary Care and Public Health, School of Public Health, Imperial College London, London, United Kingdom. E-mail: c.kyriakos20@ imperial.ac.uk

ORCID ID: https://orcid.org/00000003-0486-9152

\section{KEYWORDS}

menthol ban, tobacco flavors, European Tobacco Products Directive, tobacco control policy, tobacco industry

Received: 30 September 2021

Accepted: 13 October 2021 
(e.g. combination of sensory panels and chemical analysis $\left.{ }^{8}\right)$ withstand legal challenges?', and 'What is the feasibility of implementing each approach in more resource-constrained countries?'.

Early research supports the effectiveness of flavor bans in increasing quitting, while also highlighting the challenges. The following policy recommendations and areas for future research may maximize public health impact.

Major policy recommendations:

1. Include all tobacco products and accessories in flavor bans;

2. Accelerate implementation to stop sales of flavored tobacco quickly; and

3. Support menthol smokers in cessation efforts through smoking cessation programs and media campaigns.

Major areas of continued and future research:

1. Population-level impact of flavor bans, including smoking initiation, cessation, and tobacco-related morbidity and mortality, as well as possible unintended consequences such as illicit trade ${ }^{9}$;

2. Possible positive and negative consequences of a flavor ban on alternative nicotine products ${ }^{10,11}$; and

3. Comparative effectiveness of different regulatory approaches to ban flavors, e.g. ban on sensory perception of characterizing flavors versus total ban on flavor additives.

\section{REFERENCES}

1. European Union. Directive 2014/40/EU of the European Parliament and the Council of the European Union. Off J Eur Union. 2014;2014(April):1-38. Accessed September 27, 2021. https://ec.europa.eu/health/sites/health/files/ tobacco/docs/dir_201440_en.pdf

2. European Network for Smoking and Tobacco Prevention. Ban on menthol cigarettes: European Union member states shall prohibit the placing on the market of tobacco products with a characterising flavour. Tob Prev Cessat. 2020;6(July):40. doi:10.18332/tpc/124164

3. Erinoso O, Clegg Smith K, Iacobelli M, Saraf S, Welding K, Cohen JE. Global review of tobacco product flavour policies. Tob Control. 2020;30(4):373-379. doi:10.1136/tobaccocontrol-2019-055454

4. Chung-Hall J, Fong GT, Meng G, et al. Evaluating the impact of menthol cigarette bans on cessation and smoking behaviours in Canada: longitudinal findings from the Canadian arm of the 2016-2018 ITC Four
Country Smoking and Vaping Surveys. Tob Control. 2021. doi:10.1136/tobaccocontrol-2020-056259

5. Zatoński M, Herbeć A, Zatoński W, et al. Cessation behaviours among smokers of menthol and flavoured cigarettes following the implementation of the EU Tobacco Products Directive: findings from the EUREST-PLUS ITC Europe Surveys. Eur J Public Health. 2020;30(Suppl 3):iii34-iii37. doi:10.1093/eurpub/ckaa050

6. Hiscock R, Silver K, Zatoński M, Gilmore AB. Tobacco industry tactics to circumvent and undermine the menthol cigarette ban in the UK. Tob Control. 2020. doi:10.1136/tobaccocontrol-2020-055769

7. Joint Action on Tobacco Control. WP9: D9.3 Report on the Peer Review of the Enhanced Reporting Information on Priority Additives. Published 2020. Accessed September 27, 2021. https://jaotc.eu/wp-content/uploads/2021/04/ D9.3-Report-on-the-peer-review-of-the-enhancedreporting-information-on-priority-additives.pdf

8. European Commission. Methodology for the technical assessment of test products assisting in determining tobacco products with a characterising flavours: Application to cigarettes and roll your own products. Published 2020. Accessed September 27, 2021. https:// ec.europa.eu/health/sites/default/

9. Levy DT, Pearson JL, Villanti AC, et al. Modeling the future effects of a menthol ban on smoking prevalence and smoking-attributable deaths in the United States. Am J Public Health. 2011;101(7):1236-1240. doi:10.2105/AJPH.2011.300179

10. Li L, Borland R, Cummings KM, et al. How Does the Use of Flavored Nicotine Vaping Products Relate to Progression Toward Quitting Smoking? Findings From the 2016 and 2018 ITC 4CV Surveys. Nicotine Tob Res. 2021;23(9):1490-1497. doi:10.1093/ntr/ntab033

11. Kasza KA, Goniewicz ML, Edwards KC, et al. E-Cigarette Flavors and Frequency of E-Cigarette Use among Adult Dual Users Who Attempt to Quit Cigarette Smoking in the United States: Longitudinal Findings from the PATH Study 2015/16-2016/17. Int J Environ Res Public Health. 2021;18(8):4373. doi:10.3390/ijerph18084373 
CONFLICTS OF INTEREST

The authors have each completed and submitted an ICMJE Form for Disclosure of Potential Conflicts of Interest. The authors declare that they have no competing interests, financial or otherwise, related to the current work. G. T. Fong reports having served as an expert witness or a consultant for governments defending their country's policies or regulations in litigation, and has also served as a paid expert consultant to the Ministry of Health of Singapore in reviewing the evidence on plain/standardized packaging. C. N. Kyriakos reports funding from the Imperial College London President's PhD Scholarships. R. Hiscock reports funding by Bloomberg Philanthropies via the STOP Project - a global tobacco industry watchdog, whose mission is to expose the tobacco industry strategies and tactics that undermine public health.

\section{FUNDING}

This research was funded by Imperial College London (C. N. Kyriakos), Bloomberg Philanthropies via the STOP Project (R. Hiscock), the Canadian Institutes of Health Research (FDN-148477), the Ontario Institute for Cancer Research, and the Canadian Cancer Society (G. T. Fong).

ETHICAL APPROVAL AND INFORMED CONSENT

Ethical approval and informed consent were not required for this study.

DATA AVAILABILITY

Data sharing is not applicable to this article as no new data were created.

PROVENANCE AND PEER REVIEW

Commissioned; internally peer reviewed. 